\title{
Português para fins específicos: retomando a análise de necessidades
}

\section{Anna Maria Marques Cintra \\ Doutora em Letras-Linguística pela USP, profes- sora do Programa de Estudos Pós-graduados em Língua Portuguesa da Pontificia Universidade Católica de São Paulo.}

Lílian Ghiuro Passarelli

Doutora em Língua Portuguesa pela PUC-SP, professora na graduação e na especialização da Pontificia Universidade Católica de São Paulo.
Resumo: Retoma aspectos do ensino de lingua portuguesa para fins especificos, priorizando a Análise de Necessidades como instrumento indispensável para se conhecer o que os alunos sabem e o que não sabem a respeito do uso da linguagem em contextos específicos e, assim, planejar o curso com a devida adequação. Com breve retrospecto da iniciativa de adaptação do ensino de inglês instrumental ao ensino da lingua portuguesa, lingua materna, pontua as partes de uma Análise de Necessidades. Finaliza indicando que, na Análise de Necessidades, a motivação e a representaçăo social dos alunos são componentes importantes e determinantes para 0 sucesso do curso.

Palavras-chave: ensino de português; fins específicos; análise de necessidades
Abstract. This article brings to light aspects of teaching Portuguese for specific purposes, prioritizing needs analysis as an indispensable instrument to acknowledge what the students know and what they do not know about the use of the language to plan a course with the due adequacy. With a short retrospective over the initiative of adaptation of instrumental English educational practice to the Portuguese language as mother language, it focuses the needs analysis parts. The paper ends indicating that the students' motivation and social representation are important components to the needs analysis, so to allow a successful course development.

Key words: teaching Portuguese; specific purposes; needs analysis 


\section{Preliminares}

Este texto foi motivado pela constatação de que, no meio acadêmico, há cursos denominados Português Instrumental ou Português para fins específicos, que, na verdade, trabalham utilizando os mesmos materiais semestre a semestre, sem se valer de uma Análise de Necessidades dos alunos. Agindo dessa forma, descaracterizam a abordagem com um "ensino", muitas vezes, repleto de conteúdos gramaticais, com aulas construídas com exposições teóricas, ou mesmo com a atribuição aos alunos de leituras de textos acadêmicos que nada têm a ver com o fim específico do curso e com as necessidades do público alvo.

Optou-se, neste texto, pelo termo "fins específicos", em lugar de "instrumental", dado que tem ocorrido, entre profissionais pouco afeitos à abordagem, uma concepção de que se trata de um trabalho carregado de técnicas mecanicistas, quando, efetivamente, o ensino de línguas para fins específicos passa muito longe desse universo.

O trabalho tem como objetivo retomar e refletir sobre os aspectos dessa abordagem que já se mostrou eficaz para resolver problemas de deficiências de leitura e produção de textos, tanto de acadêmicos de diferentes áreas, quanto de profissionais do mercado de trabalho.

Não se pode aceitar a reprodução de práticas tradicionais de ensino com o nome de "fins específicos", porque parece inquestionável que, se o sujeito passou cerca de onze anos em contato com um ensino de língua materna que foi, basicamente, de cunho gramatical, ao chegar à Universidade ou mesmo à vida profissional com carências significativas no domínio da língua materna, não poderá ser submetido aos mesmos procedimentos adotados pela escola, uma vez que já deram mostras de sua ineficiência.

A rigor, a abordagem para fins específicos teria fraco interesse, se a escola tivesse propiciado uma formação linguística mais ampla e eficaz a seus alunos. Mas, em face da realidade educacional brasileira, observase, ainda, a necessidade de português para fins específicos, 
tanto em cursos universitários de diferentes áreas, como em empresas, tendo em vista "aprimorar" habilidades relativas à leitura e à escrita.

Só um novo enfoque que venha a priorizar fins específicos poderá contribuir para a superação de problemas criteriosamente identificados pelo professor. Mas isso não basta. Ele terá de assumir, também, uma mudança de postura, ao buscar meios suficientes para fazer com que os alunos ocupem o centro da ação pedagógica, como construtoies de seu próprio conhecimento, ficando ele, professor, como facilitador no processo de ensino e aprendizagem. E, para tanto, há de haver preparo adequado seja no nível didático, seja no trabalho com conteúdos de língua e linguagem, voltados para o fim específico do curso.

É provável que o desencanto com o ensino tradicional possa ser um elemento impulsionador de mudanças, mas é fundamental que junto ao impulso ocorra o preparo teórico e prático do professor para lidar de forma adequada com o que vem a ser um ensino de língua materna numa abordagem para fins específicos. Ao assumir o papel de facilitador, o professor atua como mediador na leitura e produção de textos e, diversamente do que vem se repetindo no ensino tradicional, em que o conteúdo programático se sobrepõe às pessoas, terá de garantir ao aluno uma estatura tal que ele possa participar ativa e reflexivamente do processo, em busca de respostas a suas necessidades, em torno do fim específico do curso. E essa não é uma tarefa trivial na construção de um planejamento.

Mediar impõe utilizar estratégias que facilitem o entendimento de conteúdos definidos, previamente, como fundamentais para o curso, ou seja, significa atender diretamente às necessidades com meios eficazes para que o aprendiz seja capaz de construir, ele mesmo, sentidos ao ler e ao escrever em língua materna.

Nesse contexto, a finalidade do curso tem de ser o eixo central que vai definir, por um lado, os conteúdos e, por outro, as estratégias, normalmente buscadas entre 
comparações, exemplos, textos autênticos, enfim, situações reais que façam com que o trabalho desenvolvido em todas as atividades do curso testemunhem a preocupação com a área em foco, com a linguagem voltada para as necessidades do grupo e com os objetivos e metas traçados, após, em geral, o primeiro contato com os alunos.

O presente estudo organiza-se em duas partes: a primeira, que procura refazer, em linhas gerais, a retomada de um percurso trilhado para chegar ao ensino de português para fins específicos em língua materna; e a segunda, que trata do instrumento Análise de Necessidades, entendido como indispensável para todo e qualquer curso nessa abordagem.

\section{Um retrospecto}

Retomar o percurso trilhado com a abordagem instrumental, noensino de língua portuguesa, significa uma possibilidade de, ao reorganizar alguns dados históricos, refletir sobre eles com o devido distanciamento.

A opção pela abordagem decorreu da repercussão positiva dos resultados obtidos no ensino do inglês instrumental, na PUC-SP, nas décadas de 1970 e 1980, e se concretizou com a utilização e/ou adaptação de princípios dessa prática em cursos ministrados na Universidade para áreas específicas e em empresas.

No início dos anos 1970 do século passado, a novidade no ensino de língua materna estava praticamente circunscrita a descrições estruturais, graças, em boa parte, aos estudos de Joaquim Mattoso Câmara Jr.

Eram perceptíveis as mudanças na forma de tratar a língua, quando se comparava com os estudos puramente filológicos. No entanto, os estudos estruturais não se repercutiam em modificações no manejo da língua por parte dos alunos. Falava-se em ensino comunicativo da linguagem, mas na prática não se avançava para além das descrições.

Em meio a inquietações desse tipo e à observação de que o ensino da língua inglesa na PUC-SP, sob a orientação da Professora Maria Antonieta Alba Celani, 
dava resultados positivos, já que era notório que os alunos saíam bem formados, aventamos a possibilidade de adaptar algumas estratégias para o ensino de português. Se havia um procedimento eficaz para ensinar uma língua estrangeira, não seria viável sua adaptação para o ensino da língua materna?

Só havia uma maneira de saber: tentar. E, para tanto, era necessário conhecer o que vinha a ser inglês instrumental e procurar desvendar o que seria, na prática, leitura intensiva e leitura extensiva. Em língua materna, praticamente, quase nada havia que pudesse abrir novos horizontes, em especial para um trabalho com leitura.

Para ultrapassar o período de curiosidade, buscou-se frequentar, primeiro, um curso de inglês instrumental, para vivenciar o processo ao mesmo tempo que se observava o que era feito e, posteriormente, uma disciplina de Metodologia de Línguas Instrumentais, ministrada na pós-graduação pelos professores M. Scott e J. Holmes.

Esses dois cursos abriram perspectivas novas e permitiram reunir forças para o enfrentamento de dois desafios: o da pesquisa e o da organização de cursos ministrados na Universidade e em empresas. Com dedicação e humildade, erros percebidos eram corrigidos e, assim, gradativamente se consolidava uma certeza: a abordagem instrumental ou para fins específicos oferecia vantagens incontestáveis tanto para o professor quanto para o aluno.

Para o professor, na medida em que propiciava um novo olhar sobre o desempenho da tarefa de ensinar, graças a uma mudança de postura. Era preciso sair do papel de professor que "dava" a matéria e a cobrava em provas, para assumir o de animador de um processo de ensino, segundo o qual caberia ao próprio aprendiz construir seu aprendizado. E isso impunha um tratamento diferente em relação à gramática, que passaria de fim a meio, dado que, para priorizar o trabalho com a linguagem em ação em fins específicos, o texto escrito ou oral teria de ocupar o primeiro plano. 
Ainda no atinente ao professor, um aspecto se destacava como novidade: a satisfação no exercício da tarefa de ensinar. Com efeito, ele tinha recursos para chegar mais próximo das necessidades do aluno em relação à língua e por isso seria capaz de dimensionar melhor as tarefas, tendo em vista atingir objetivos e cumprir metas previamente traçadas.

Quanto ao aluno, era patente a vantagem, pois não mais ele estaria submetido a regras gramaticais, textos teóricos, mas toda a teoria estaria vinculada a situações concretas relacionadas à finalidade do curso.

A primeira experiência, ainda titubeante, foi num curso de língua portuguesa na Universidade. A cada semana, o que era produzido pelos alunos era comentado, por escrito, pelas professoras, retornando a eles para conhecimento. Na mesma aula os textos voltavam para as professoras que os organizavam em pastas individuais, permitindo, assim, um acompanhamento contínuo e individualizado dos trabalhos. Talvez o aspecto mais importante nessa primeira tentativa tenha sido a alteração de comportamento profissional. Com efeito, não fazia parte da prática profissional pensar em limites determinados pelo tempo, pelas condições reais de trabalhos. Era freqüente terminar um semestre com frustrações por não ter conseguido atingir todo o conteúdo previsto, ou por não ter clareza do aproveitamento efetivo dos alunos.

Com a abordagem para fins específicos, tomava-se consciência de que, como parte do processo, o professor deveria levar em consideração, no planejamento do curso, também suas possibilidades reais, ajustar os objetivos às necessidades de cada grupo, estabelecer metas alcançáveis, levar em conta as condições de trabalho.

Osresultadosiamsendoconquistadospoucoapouco, com as dificuldades inerentes à adaptação de materiais de língua inglesa e à criação de materiais específicos para língua portuguesa. Mas, de toda forma, valia a pena investir nessa empreitada, pois tudo que se fazia estava atrelado à finalidade de cada curso, ao "conhecimento" das necessidades dos alunos. $\mathrm{O}$ velho planejamento feito 
às cegas, que, praticamente se repetia ano a ano, podia ser, finalmente, modificado, ou antes, desenhado com base nos resultados de uma Análise de Necessidades aplicada a cada novo grupo que se constituía. E, diante de cada grupo de alunos, eram buscadas estratégias que pudessem responder às necessidades peculiares daquele detectadas.

Vale mencionar que os próprios conceitos de objetivos e metas sofreram considerável mudança. Antes eram tratados, praticamente, como sinônimos; na abordagem para fins específicos ganharam clara diferença: objetivos referiam-se aos propósitos (em geral qualitativos) do curso, enquanto metas referiam-se a marcos quantitativos a ser atingidos. Essa diferença que, para algumas áreas é comum, para o ensino de língua materna não parecia ser.

Com base em orientações da abordagem para fins específicos, atividades de ensino sofreram mudanças. Passou-se a valorizar a motivação tanto do aluno para aprender, como do professor para ensinar.

\section{A Análise de Necessidades}

Compreender a Análise de Necessidades para além de um mero diagnóstico é fundamental, quando se pretende trabalhar com a abordagem para fins específicos. Vale enfatizar, como lembra HOLMES (1981b, p.117), que a construção do instrumento se faz tendo em mente que ele, "simultaneamente, fornece informações ao professor e prepara o aluno para interagir com uma forma mais dinâmica e engajada de aprender".

Na prática, o aluno não fica com a sensação de um diagnóstico que permite ao professor concluir apenas o que ele não sabe; pelo contrário, a expectativa é de que ele se sinta instigado a não apenas responder a umas poucas questões, como também a executar, já no primeiro encontro, tarefas relacionadas à finalidade do curso.

A razão de serem poucas as perguntas do instrumento tem como finalidade não tomar o tempo do aluno com questões irrelevantes para o planejamento, já que o momento da tarefa tem de ser também dedicado 
a atividades em que o aluno dá conta de como as executa, para o confronto com sua autoimagem e com sua própria reflexão.

Assim, uma Análise de Necessidades bem construída pode "captar a competência inicial do aluno e apontar para um desempenho possível" (HOLMES, 1981b, p.120), além de dar a ele uma nova dimensão de curso de língua portuguesa, longe das recorrentes informações gramaticais a que já teve acesso durante praticamente toda sua vida escolar.

A mudança que se opera costuma tornar o aluno ciente de suas possibilidades como produtor de linguagem em língua materna, o que gera um ambiente mais produtivo em sala de aula e propicia ao professor trabalhar não apenas com o que os alunos não sabem, como também valorizar o que sabem, como contribuição para tornar mais evidente a autoestima, normalmente muito desgastada por um ensino reprodutor de regras.

\section{A elaboração do instrumento}

$\mathrm{Na}$ construção do instrumento, cada uma de suas partes, dada sua função no conjunto, deve ser cuidadosamente elaborada, em consonância com um princípio básico: só podem constar questões que tenham relevância para o planejamento do curso. Em vista disso, diante de cada questão, o professor tem de calcular o que será feito com a resposta. Isso permitirá descartar as que forem irrelevantes.

A primeira, nem sempre observada com atenção, diz respeito à explicitação, de forma sintética, dos objetivos da atividade que se inicia. Admite-se que os alunos têm o direito de saber para que estão realizando uma Análise de Necessidades.

A segunda parte é a que contém dados de identificação de cada aluno e do contexto no qual ele se insere, permitindo ao professor conhecer individual e coletivamenteogrupo.Algumasdasquestões, normalmente importantes para o planejamento, são a idade dos alunos; o período ou série em que se encontram, quando o grupo 
for heterogêneo; algo que permita distinguir alunos que só estudam daqueles que têm atividades de estágio ou de trabalho concomitante com o curso, ou a função, quando se tratar de empresa. As questões elaboradas nesta parte dão ao professor conhecimentos médios sobre o grupo, o que é importante para o dimensionamento mais adequado das atividades.

A terceira parte busca levar o aluno a registrar dados de sua autoimagem, em relação aos aspectos relativos à finalidade e objetivos traçados para o curso. $\mathrm{O}$ pequeno questionário que pode combinar questões quantitativas e qualitativas deve dar uma ideia aproximada do que o aluno sabe, do que pensa que sabe e do que até desconhece que sabe em relação à linguagem.

Embora muitos professores defendam questões abertas como mais informativas, parece sempre preferível priorizar questões fechadas, por três razões práticas: primeiro, porque o professor dispõe de pouco tempo para avaliar os resultados e construir seu planejamento de curso; segundo, porque categorizar questões abertas não é tarefa simples de ser realizada com segurança; terceiro, porque a qualidade dos dados não depende de ser a questão aberta ou fechada, mas da maneira pela qual a questão foi formulada.

A quarta parte diz respeito à realização de uma atividade relacionada à finalidade do curso. Com ela o aluno executa uma "ação" individual que busca, de certa forma, conferir sua auto-imagem com o que faz.

Como, normalmente, a grande carência em língua materna diz respeito à produção de textos autênticos na área do curso, a leitura pode passar despercebida, ainda que seja entrave significativo para a produção de textos acadêmicos e mesmo profissionais. Assim, é sempre produtivo solicitar a leitura de um pequeno texto autêntico que possa ser tomado como fonte para a produção de textos escritos ou orais, caso não seja a leitura um dos focos priorizados.

O fundamental é que a atividade proposta para uma ação seja inteiramente articulada ao fim específico 
do curso, tenha significado autêntico na área e seja executada por todos os alunos. Além disso, cada atividade tem de ser introduzida de forma clara, precisa e completa, pois imprecisão ou incompletude na instrução podem comprometer, sensivelmente, o resultado.

A quinta e última parte corresponde a um novo pequeno questionário, no qual o aluno seja instado a refletir sobre como executou a atividade proposta, o que, na construção do instrumento, exige conexão entre as partes, em especial entre as três últimas.

\section{O ensino para fins específicos}

Apráticatemmostradoquealunoscomautoimagem positiva ou negativa exacerbadas, normalmente, oferecem, respectivamente, mais resistência ou dificuldade para aprender, carecendo de atividades específicas que possam auxiliá-los a encontrar maior equilíbrio na percepção de suas potencialidades.

A conexão entre as partes pode, por sua vez, levar o aluno a refletir sobre sua auto-imagem, sobre sua competência, facultando a ele ver a Análise de Necessidades como um misto de ideias e ações capaz de mostrar um pouco do contexto no qual o curso vai se dar. Do ponto de vista do professor, a conexão favorece o conhecimento de cada um dos alunos e a construção do perfil do grupo, propiciando, portanto, um ensino mais focalizado nas necessidades.

$\mathrm{Na}$ abordagem para fins específicos, os problemas gramaticais surgem e são trabalhados de forma objetiva em textos, preferencialmente autênticos, sem preocupação de resolver tudo que diz respeito ao tópico ou de focalizar a metalinguagem. O que importa é o fenômeno gramatical, observado e definido segundo sua relevância para a aprendizagem do aluno em face das finalidades do curso.

A insistência neste ponto decorre da constatação de uma prática eivada de situaçôes que permitem até mesmo parodiar ALVES (1981, p.23), quando fala sobre o ensino de ciência: frequentemente, o professor fracassa no ensino da gramática, porque apresenta soluções perfeitas 
para problemas que nunca chegaram a ser formulados e compreendidos pelo aluno. De fato, no ensino de língua portuguesa, grandepartedostemas-problema apresentados aos alunos nunca foram objeto de preocupação deles, nem o professor foi suficientemente convincente para demonstrar sua importância no desempenho linguístico. $\mathrm{O}$ que se encontrou mais comumente foi um ensino que se fez para a própria escola e não para a vida do educando.

Como lembra VIAN JR. (2003, p.3), o ensino instrumental envolve conhecimentos específicos de linguagem, de pedagogia e da área de interesse do aprendiz. Logo, o professor tem de estar preparado em sua área de especialidade e se dispor a buscar subsídios na literatura pedagógica e na própria área específica, para ser capaz de se valer, com adequação, de textos autênticos.

Abrir mão de uma Análise de Necessidades em cursos para fins específicos pode levar ao insucesso mesmo que o professor seja muito experiente. Entretanto, em situações especiais, é possível buscar dados não numa Análise de Necessidades padrão, mas em produções autênticas dos próprios alunos. Isso pode acontecer em cursos ministrados em empresas, pois, por razões de planejamento, o intervalo entre o primeiro e o segundo encontro com o grupo poderá ser muito próximo, inviabilizando a elaboração, aplicação e avaliação de uma Análise de Necessidades.

Nesse caso, pode-se solicitar, previamente, de cada um dos futuros alunos, um ou dois textos produzidos em situação normal de trabalho, para serem analisados. O levantamento das dificuldades identificadas pode ser um bom ponto de partida para o planejamento do curso que, naturalmente, terá de ser reavaliado a cada passo, pelo professor.

\section{Considerações finais}

Ao propor, como fez HOLMES (1981a), que a Análise de Necessidades se constitua já numa atividade introdutória do curso, busca-se identificar se a autoimagem dos alunos é suficiente para consolidar 
autoconfiança ou se caberá ao professor desenvolver, durante o curso, estratégias que ajudem a conquistá-la, programando, inclusive, etapas que progressivamente permitam mostrar melhora.

Conhecer, mesmo que parcialmente, a representação social que cada um tem de si, em face das finalidades do curso, as competências fundamentais para os fins propostos, bem como contar com a motivação dos alunos e do próprio professor, podem fazer diferença desde o primeiro encontro com os alunos.

A questão das representações sociais evidencia-se, quando se busca a construção da autoimagem do aluno e pode se confirmar com a reflexão a que ele é levado a fazer, após ter executado a atividade específica.

Adverte SPINK $(1995$, p.8) que as representações sociais, entendidas como resultado da elaboração do conhecimento pelo sujeito,

são essencialmente dinâmicas; são produtos de determinações tanto históricas como do aquie-agora e construções que têm uma função de orientação: conhecimentos sociais que situam o indivíduo no mundo e, situando-o, definem sua identidade social - o seu modo de ser particular, produto de seu ser social.

Nesse sentido, numa Análise de Necessidades, as questões que procuram situar os indivíduos no universo específico da linguagem, para um determinado fim, têm de ser admitidas segundo um processo de tal forma dinâmico que seja possível formar algumas concepções no momento mesmo das respostas, graças ao contexto constituído.

Em relação à competência, observa-se, segundo PERRENOUD (1998), sua estreita articulação com o agir, uma vez que se trata de uma capacidade de ação em face de uma situação complexa e singular. Dessa forma, a emergência da ação inibe, de certa maneira, a reflexão serena e tranquila e leva o sujeito a atuar até mesmo 
com incertezas, já que ele pode não dispor de todas as informações e instrumentos para as respostas.

A motivação constitui fator importante desde a aplicação da Análise de Necessidades. Embora o aluno possa ter curiosidade em relação ao curso, já demonstrando interesse espontâneo, cabe ao professor não descuidar da motivação que pode ser acionada por questões bem elaboradas, pelas atividades selecionadas dentro do universo do fim específico.

Finalizando, pontuam-se alguns aspectos importantesnaabordagemquesãodiretamentedecorrentes do resultado de uma Análise de Necessidades: o desenho do curso; a motivação do aluno para aprender e a do professor para ensinar que aumentam, significativamente, na medida em que as tarefas são dimensionadas para necessidades detectadas; o acerto na escolha das estratégias de ensino a partir do perfil do grupo; uma mudança de atitude do professor ao ensinar, adquirindo maior segurança diante dos objetivos e metas traçados. Em suma, por meio de uma Análise de Necessidades pode-se chegar mais perto do ideal de fazer da educação linguística algo mais centrado no uso da linguagem, que leve em conta a autoafirmação do aluno. 


\section{Referências}

ALVES, R. Filosofia da linguagem. São Paulo: Brasiliense, 1981.

HOLMES, J. What do we mean by ESP? Working Papers 2, São Paulo: Projeto Nacional de Ensino de Inglês Instrumental em Universidades Brasileiras, CEPRIL, PUCSP, 1981a.

HOLMES, J. Needs analysis: a rationele for course design. The ESPecialist, São Paulo: EDUC, n.3, jun. 1981b.

PERRENOUD, P. De l'alternance à l'articulation entre théories et pratiques dans la formation initiale des enseignants. In: TARDIF, M.; LESSARD, C.; GAUTHIER, C. (Orgs.). Formation des maîtres et contextes sociaux: perspectives internationales. Paris: PUF, 1998.

SPINK, M.J. (Org.). O conhecimento no cotidiano: as representações sociais na perspectiva da psicologia social. São Paulo: Brasiliense, 1995.

VIAN Jr., O. O ensino de inglês instrumental para negócios, a Lingüística sistêmico-funcional e a teoria de gênero/registro. The ESPecialist, São Paulo: EDUC, v.24, n.1, p. 1-16, 2003. 